\title{
A Review of the Core Concept of the Cambridge Handbook of Situated Cognition
}

\author{
WU Guoliang* \\ Zhejiang Yuexiu University of Foreign Languages
}

*Corresponding Authors: WU Guoliang, Zhejiang Yuexiu University of Foreign Languages

\begin{abstract}
The Cambridge Handbook of Situated Cognition edited by Dr. Robbins and Aydede (2009) is a valuable and professional guide to the new movement in cognitive science. Each chapter of the book deals with either a specific area of empirical research or a specific sector of the conceptual foundations underlying this research. All the chapter authors are leading figures in the emerging interdisciplinary field of situated cognition, including representatives from philosophy, psychology, neuroscience, linguistics, and anthropology. This paper is not a book review. It is only a review of the core concepts of the book including views on the embodied mind, the embedded mind, the extended mind, the dynamic interaction, and the ecological rationality.
\end{abstract}

Keywords: core concept; embodied; embedded; extended; mind; dynamic interaction; ecological rationality

\section{INTRODUCTION}

Since its inception some fifty years ago, cognitive science has undergone a number of sea changes. Perhaps the best known is the development of connectionist models of cognition as alternatives to classical, symbol-based approaches. A more recent - and increasingly influential - trend is that of dynamical-systems-based, ecologically oriented models of the mind. Researchers suggest that a full understanding of the mind will require systematic study of the dynamics of interaction among mind, body, and world.

(Robbins \&Aydede, 2009)

As we know, people in many fields now pay more and more attention to the study of the mind. The book in discussion is the right one for us to read.

All the essays revolve around the connotation and extension of the situated cognition. Before discussing the core concepts, let's see the basic implication and adopted principle of the situated cognition. situated can be understood as emphasizing the contextual, dynamic, systemic, nonlocalized aspects of the mind, mental operations, identity, organizational behavior, and so on. (Clancey, 2009: 17)

The definition of the word situated is also a key idea for us to remember before we make a study of situated cognition.

Gallagher (2009:47) points out: They ( refers to the philosophers Dewey et al) remind us that cognition is not only pragmatically situated but also always socially situated, not simply in the sense that die world is populated with others with whom we communicate but also in the sense that this communication and interaction shape our cognitive abilities from the very beginning. They push us to realize that cognition not only is enactive but also elicited by our physical and social environment; that it not only involves a deeply embodied and temporally structured action but also is formed in an affective resonance generated by our surroundings and by others with whom we interact.(47)

We hold that above passage clearly explain the relationship between the cognition and the pragmatics.

As a way of organizing our description of theory and research within social psychology that pertains to situated cognition, Smith \& Conrey (2009) adopt four major principles advanced by Smith and 
Semin (2004). These are intended to capture four interrelated and partially overlapping themes that are common to social psychology and situated cognition. The principles are as follows: (1) Cognition is for the adaptive regulation of action, and mental representations are action oriented; (2) cognition is embodied, both constrained and facilitated by our sensorimotor abilities as well as our brains; (3) cognition and action are situated in the sense of being contingent on specific aspects of the agent's social environment; (4) cognition is distributed across brains and the environment and across social agents. (Smith \& Conrey2009: 456).

Based on the above mentioned frame and the exposition of the whole book, we are to make a brief review on the core concept which is throughout the book.

\section{VIEWS ON THE EMBODIED MIND}

\subsection{Robbins \& Aydede (2009 : 4) point out}

Without the cooperation of the body, there can be no sensory inputs from the environment and no motor outputs from the agent.

In terms of embodied mind, it is not very familiar to people whose speciality is even linguistics. This is a completely new topic that has something to do with cognitive linguistics and sociolinguistics.

From a foundational perspective, the concept of embodiment matters because it offers help with the notorious "symbol-grounding problem," that is, the problem of explaining how representations acquire meaning (Anderson, 2003; Hamad, 1990; Niedenthal, Barsalou, Winkielman, Krauth-Gruber, $\&$ Ric, 2005).

This approach to the symbol-grounding problem makes it natural for us to attend to the role of the body in cognition. After all, our sensory and motor capacities depend on more than just the workings of the brain and spinal cord; they also depend on the workings of other parts of the body, such as the sensory organs, the musculoskeletal system, and relevant parts of the peripheral nervous system (e.g., sensory and motonerves).(Robbins\&Aydede 2009:4)

Robbins \& Aydede (2009:4) also point out : On the embodied view, the classical picture of the mind is fundamentally flawed. In particular, that view is belied by two important facts about the architecture of cognition: first, that modality-specific representations not amodalrepresentations, are the stuff out of which thoughts are made; second that perception, thought, and action are coconstituted, that is, not just causally but also constitutively interdependent .

We hold that these two facts are really important for us to understand why the authors assume that the classical picture of the mind is fundamentally flawed.

There are two ways in which the cognition can be embodied, which are discussed among scholars. As explained by Robins\& Aydede (2009):

Accordingly, we should distinguish two ways in which cognition can be embodied: on-line and offline (Niedenthal et al., 2005; Wilson, 2002). The idea of on-line embodiment refers to the dependence of cognition - that is, not just perceiving and acting but also thinking - on dynamic interactions between the sensorimotor brain and relevant parts of the body: sense organs, limbs, sensory and motor nerves, and the like. This is embodiment in a strict and literal sense, as it implicates the body directly. Off- line embodiment refers to the dependence of cognitive function on sensorimotor areas of the brain even in the absence of sensory input and motor output. This type of embodiment implicates the body only indirectly, by way of brain areas that process body-specific information (e.g., sensory and motor representations).

To illustrate this distinction, let us consider a couple of examples of embodiment effects in social psychology (Niedenthal et al., 2005). First, it appears that bodily postures and motor behavior influence evaluative attitudes toward novel objects. (p4)For the case study, see Cacioppo, Priester, \& Bernston, 1993.

The following case study is worth doing, which helps to understand the the feature of cognition and the function of embodiment.

This looks to be an effect of on-line embodiment, as it suggests that actual motor behaviors, not just activity in motor areas of the brain, can influence attitude formation. Contrast this case with another 
study of attitude processing. Subjects were presented with positively and negatively valenced words, such as love and hate, and asked to indicate when a word appeared either by pulling a lever toward themselves or by pushing it away (Chen \& Bargh, 1999).

In each trial, the subject's reaction time was recorded. As predicted, subjects responded more quickly when the valence of word and response behavior matched, pulling the lever more quickly in response to positive words and pushing the lever away more quickly in response to negative words. Embodiment theorists cite this finding as evidence that just thinking about something — that is, thinking about something in the absence of the thing itself - involves activity in motor areas of the brain. This result exemplifies off-line embodiment, insofar as it suggests that ostensibly extramotor capacities like lexical comprehension depend to some extent on motor brain function - a mainstay of embodied approaches to concepts and categorization (Glenberg \& Kaschak, 2002; Lakoff \& Johnson, 1999).(p5)

The distinction between on-line and off- line embodiment effects makes clear that not all forms of embodiment involve bodily dependence in a strict and literal sense. Indeed, most current research on embodiment focuses on the idea that cognition depends on the sensorimotor brain, with or without direct bodily involvement. (In that sense, embodied cognition is something of a misnomer, at least as far as the bulk of research that falls under this heading is concerned.) (Robbins \&AYdede, 2009 ,p5)

Husserl had outlined a concept of embodiment that distinguished Descartes' concept of the objective body (the body as an object extended in space, or as studied by biological science) and the lived body [Leib], which is the body that I experience and with which I act. It is the lived body that gears into the affordances of the world. (p42, 20)

\subsection{Discourse Comprehension from an Embodied Perspective}

There is very little research on discourse comprehension from an embodied perspective Just as motor resonance has been demonstrated at the word and the sentence level, it has been shown to occur at the level of discourse. Zwaan \&Kaschak (2009:376)

The following information is extremely useful for scholars doing the similar research.

Zwaan \& Kaschak(2009: 377) point out: The assumptions that are generally made in discourse comprehension research are(a) information that is currently in working memory is more accessible (i.e., more highly activated) than information that is not, and (b) when probed, more accessible information will yield faster responses than less accessible information. Therefore, the presentation of probe words associated with the contents of working memory should facilitate responses. In accordance with this logic, various studies have demonstrated that the contents of working memory during comprehension reflect the nature of the described situation. Probe-word responses are faster when the probe refers to

- A present entity rather than an absent entity (Anderson, Garrod, \& Sanford, 1983; Carreiras, Carriedo, Alonso, \& Fernandez, 1997).

- A present rather than an absent feature (Kaup \& Zwaan, 2003).

- A present object rather than a distant object (Glenberg, Meyer, \& Lindem, 1987; Morrow, Bower, \& Greenspan, 1989; Morrow, Greenspan, \& Bower, 1987; Rinck \& Bower, 2000).

- An ongoing event rather than a past event (Zwaan, 1996; Zwaan, Madden, 8r Whitten, 2000).

- A current goal rather than an accomplished one (Trabasso 8c Suh, 1993).

- A visible entity rather than an occluded one (Horton \& Rapp, 2002). (377)

\section{VIEWS ON THE EMBEDDED MIND}

3.1. After comprehending the embodied mind, now let's see the embedded mind, which is much easier for us to understand. And also the two are related to each other.

Generally speaking, the embedded approach aims to minimize the amount of internal representation used to model the human performance of cognitive tasks (Ballard et al., 1997; Clark, 1997, chap. 8; McClamrock, 1995, chap. 6) (p105) 
In order to explain it with practical example, let's see the following passage given by Rupert (2009 106): To illustrate, consider Clark's (1995) example of finding the photo-development counter at a supermarket. Given the market dominance of Kodak, the area above or around the photo-development counter is normally splashed with yellow. This suggests a simple strategy to the consumer in search of the photo counter: enter the supermarket and swivel one's head about to look for a large patch of yellow.

There are three tactical principles provided by Rupert (2009:106)which will help to understand the example:

At work in this example are three tactical principles by which embedded models minimize the subject's use of internal representational resources. First, the subject need not explicidy represent - in working memory or any other sort of cognitive work space - any very elaborate theory or conception of photo counters. Second, the subject represents what might be called a "coarse-grained" property: the subject looks for a large patch of yellow, not one of any particular size. Third, the subject collects only the information she needs.

Robbins\& Aydede (2009:6) point out: It seems natural to think of cognition as an interaction effect: the result, at least in part, of causal processes that span the boundary separating the individual organism from the natural, social, and cultural environment. To understand how cognitive work gets done, then, it is not enough to look at what goes on within individual organisms; we need to consider also the complex transactions between embodied minds and the embedding world. One type of such a transaction is the use of strategies for off-loading cognitive work onto the environment, a useful way to boost efficiency and extend one's epistemic reach.

One of the best articulations of the idea of cognitive off-loading involves the concept of epistemic action (Kirsh \& Maglio, 1994) an epistemic action is an action designed to advance the problem solver's cause by revealing information about the task that is difficult to compute mentally. The bestknown example of epistemic action involves the computer game Tetris, the goal of which is to orient falling blocks (called "zoids") so they form a maximally compact layer at the bottom of the screen.

Another example for the arrangement of things see the introduction by Kirsh (1995).

Both of these examples of epistemic action point to the importance of minimizing load on internal memory, on working memory in particular. This echoes the twin themes of Brooks's (1991) "world as its own model" (p. 140) and O'Regan's (1992)"world as an outside memory" (p. 461).

\subsection{Myin \& O'Regan (2009:187): has a special explanation for The Hypothesis of the World as an Outside Memory}

To begin to answer this question, consider the light in a refrigerator (Thomas, 1999). Unless we knew better, we would believe that the refrigerator's light is always on. Indeed, whenever we open the door to look at it, it is on. It seems continuously on, not because it is always on, and certainly not because we continuously see it as being on, but because it is on whenever we look.

In a similar vein, we suggest, the scene we are confronted with seems to be detailed, not because we see all of the details all of the time but because we find the details whenever we look for them.

That is, the elements of the scene that are in peripheral vision or are currently not attended to are seen only in a secondary sense. The retina registers these elements, but we do not see them fully as we see something we attend to. Only when we turn to them and scrutinize them, do we actually see all the detail. (p187)

The approach proposed by Myin \& O'Regan can be called the hypothesis of the world as an outside memory, following O'Regan (1992), because of the emphasis on the fact that it is the world itself, rather than some internal memory store, that is continually interrogated and dealt with. (p187)

The common idea here is that, instead of building up detailed internal models of the world that require continuous and costly updating, it pays to look up relevant information from the world on an asneeded basis. In other words, "rather than attempt to mentally store and manipulate all the relevant details about a situation, we physically store and manipulate those details out in the world, in the very situation itself' (Wilson, 2002, p. 629) (p6 50). (97) 
The embedding thesis, then, goes hand in hand with what Clark (1989) calls the "007 principle."The key meaning is: know only as much as you need to know to get the job done.

Embedding, in turn, goes hand in hand with embodiment, as off-loading cognitive work depends heavily on sensorimotor capacities such as visual lookup, pattern recognition, and object manipulation. Epistemic actions, for instance, typically re) quire embodiment in a strict and literal sense, as they involve real-time dynamic interaction with the local physical environment. (p7)

From the above, we can see the close relationship between the embedding and the embodiment.

\section{VIEWS ON THE EXTENDED MIND}

Views on the extended mind have also been discussed by many scholars. Rupert (2009: 96) points out : Consider first the view that cognitive processes extend beyond the boundary of the organism. The intimacy of the human organism's interaction with its environment during cognitive processing suggests that those cognitive processes literally comprise elements of the environment beyond the boundary of the human organism (Clark \& Chalmers, 1998). I shall refer to this view as the "hypothesis of extended cognition," or HEC. As he understands it, HE C entails that the human mind is extended. Accordingly, the subject matter of HEC (i.e., the kind of cognition at issue) had better be the sort that bears on the location of the mind. This seems fair enough. The explananda of cognitive science are various mental capacities broadly pertaining to belief formation, such as the capacities to reason, perceive, remember, construct theories, and use language. Thus, whatever model of cognition we ultimately adopt will be a model of the mind's activities or capacities; and if the activities of a mind take place at a particular spatiotemporal location, that mind is at least partly at that location.5 On this view, a given mind has a location in space-time and, according to HEC, this location includes points outside the skin bag, as Andy Clark (2003) has colorfully dubbed the boundary of the human organism. (p97)

Robbins\& Aydede (2009) hold: Assigning an important explanatory role to brain-body and agentenvironment interactions does not constitute a sharp break from classical cognitive science. Both the embodiment thesis and the embedding thesis can be seen as relatively modest proposals, given that they can be accommodated by relatively minor adjustments to the classical picture, such as the acknowledgment that "not all representations are enduring, not all are symbolic, not all are amodal, and not all are independent of the sensory and effector systems of the agent" (Markman \& Dietrich, 2000, p. 474; see also Vera \& Simon, 1993) (p7)

The same cannot be so easily said, however, of the claim that cognition is extended---the claim that the boundaries of cognitive systems lie outside the envelope of individual organisms, encompassing features of the physical and social environment (Clark \& Chalmers, 1998; Wilson, 2004; Robbins \&Aydede 2009:7-8). In this view, the mind leaks out into the world, and cognitive activity is distributed across individuals and situations. This is not your grandmother's metaphysics of mind; this is a brave new world. Why should anyone believe in it?

One part of the answer lies in the promise of dynamical systems theory - the intellectual offspring of dassical control theory, or cybernetics (Ashby, 1956; Wiener, 1948; Young, 1964) - as an approach to modeling cognition (Beer, 1995; Thelen \& Smith, 1994; van Gelder, 1995).

In short, insofar as the mind is a dynamical system, it is natural to think of it as extending not just into the body but also into the world. The result is a radical challenge to traditional ways of thinking about the mind, Cartesian intemalism in particular. (Robbins \& Aydede 2008: 8)

More generally, Adams and Aizawa (2008) point out, it is one thing to say that cognitive activity involves systematic causal interaction with things outside the head, and it is quite another to say that those things instantiate cognitive properties or undergo cognitive processes. Bridging this conceptual gap remains a major challenge for defenders of the extended mind. (p9)

\section{VIEWS ON THE DYNAMIC INTERACTION}

Using the tools of dynamical systems theory, one can describe in a mathematically precise way how various states of a cognitive system change in relation to one another over time. Because those state changes depend as much on changes in the external environment as on changes in the internal one.( Robbins \& Aydede\}(2009: 8) 
Eliasmith (2009) points out: Note that for some dynamicists, taking dynamics seriously means holding a fairly strong embedded view: "In this vision, the cognitive system is not just the encapsulated brain; rather, since the nervous system, body, and environment are all constantly changing and simultaneously influencing each other, the true cognitive system is a single unified system embracing all three" (van Gelder, 1995, p. 373). For dynamicists, then, a distinction between the system and the system's environment becomes very difficult - system boundaries become obscure. Dynamicists often claim that this result is a unique strength of the dynami cist approach and an accurate reflection of the true state of cognitive systems (Port \& van Gelder, 1995)（p148]

Elisasmith (2009) points out: The neural engineering framework (NEF) is a general theory of neurobiological systems proposed in Eliasmith and Anderson (2003). The theory consists of three quantified principles that characterize neural representation, computation, and dynamics. In this discussion, I focus on the third principle. It is stated in Eliasmith and Anderson (2003) as follows: "Neural dynamics are characterized by considering neural representations as control theoretic state variables. Thus, the dynamics of neurobiological systems can be analyzed using control theory" (p. $15)$.

Although succinct, this principle makes plain how the difficulties faced by symbolicism, connectionism, and dynamicism are addressed. In short, the systematic mapping between model time and real time is accomplished in virtue of the fact that the representations whose dynamics are expressed by control theoretic equations are precisely neural representations. This means that the various time constants of single neurons are mapped onto appropriate time constants in model neurons. (p142, 9)

Here, the importance of the time parameter has been expressed. Just as Merleau-Ponty (1962) points out: Temporality is in some way a "dimension of our being"(415). And just because of this, the situated cognition is translated as “现场即席认知” by some linguists. (See GU, Y.1999)

\subsection{Now Let's See A Typical Dynamic System.}

Eliasmith (2009) points out: The importance of acknowledging system boundaries cannot be overstated when pursuing system analysis (p149,26).Blurring, shifting, or removing system boundaries, as dynamicist and embedded agent theorists often advocate, is seriously detrimental to making progress in our explanations of such systems. (p149, 41).

As a result, considering a cognitive system (constituted by brain, body, and world) as Figure 8.4. Brain, body, and world as controllers and plants. Drawing such system boundaries and making plantcontroller distinctions make clear the differences between subsystems and their interactions. a single unified system is both impractical and uninformative from a scientific point of view .(p149,50)-

This leads naturally to the second point: that the introduction of the notion of control helps to categorize different kinds of subsystems.

A typical dynamical system in control theory consists of a plant and a controller. The plant is a physical system whose inputs we would like to change to result in particular outputs from that system. The controller plays the role of producing the necessary inputs to result in those particular outputs. This basic distinction is one that helps us understand the different roles brain, body, and world play in an overall explanation of a behaving agent in an environment. With this distinction, we can see what is special about the brain. We have fairly good physical theories that can be used to explain the kinetics and dynamics of bodies and of the world. However, we have little idea how to understand the more complex dynamics found in the brain. As a result, it is natural to consider the brain as the controller of the body as a plant, together acting as controller for the environment as a plant $(149,31)$

\subsection{Dynamic Difficulties}

Eliasmith (2009) holds that given the preceding discussion, it seems that the history of cognitive science teaches us three main lessons about dynamics. The first, noted most effectively by the dynamicists, is that cognitive systems are organisms embedded in natural environments to which they are dynamically coupled. As a result, it is highly unlikely that addressing the organism's cognitive behaviors independendy of temporal constraints on those behaviors will result in explanatorily fruitful theories. The second lesson is that model time and real time must be systematically related. The third 
and final lesson is that, even once an explicit mapping has been made between model time and organism time, more work must be done to understand truly cognitive dynamics. (142)

\section{VIEWS ON THE ECOLOGICAL RATIONALITY}

\subsection{In The Section of Ecological Rationality as a form of Situated Cognition, Brighton \& Todd (2009) propose :}

Ecological rationality depends on intelligent agents deploying their various decision strategies in particular situations, sensitive to the structure of the environment in which they are embedded.

This sounds like cognition situated in specific settings - but can we say more precisely in what way the study of ecological rationality is related to the situated movement in cognitive science? In broadterms, and to varying degrees, situated-cognition approaches view "intelligent human behavior as engaged, socially and materiallyembodied activity, arising within the specific concrete details of particular (natural) settings, rather than as an abstract, detached, general-purpose process of logical or formal ratiocination" (Smith 1999, p. 769).

At this point we lay down what we take to be some key characteristic features of situated approaches to studying cognition and how they apply to ecological rationality. The dimensions we consider are taken from Smith's (1999) characterization of situated approaches in terms of six key dimensions: located, concrete, engaged, specific, embodied, and social.

\section{Located}

The significance of being located arises when we adopt the view that "context dependence is a central and enabling feature of human endeavor" (Smith, 1999, p. 769).

\section{Concrete}

The issue of concreteness refers to the view that "constraints of realization and circumstance are viewed as of the utmost importance" (Smith, 1999, p. 769).

\section{Engaged}

The property of engagement considers how "ongoing interaction with the surrounding environment is recognized as primary"(Smith, 1999, p. 769).

\section{Specific}

Considerations of specificity refer to the fact that "what people do is seen as varying, dramatically, depending on contingent facts about their circumstances" (Smith, 1999, p. 769).

\section{Embodied}

The importance of embodiment refers to the fact that "material aspects of agents' bodies are taken to be both pragmatically and theoretically significant" (Smith, 1999, p. 769].

\section{Social}

Being social means "being located in humanly constructed settings among human communities" (Smith, 1999, p. 769).

When giving explanation for the theory of situated cognition, Brighton\& Todd(2009) regard the ecological rationality as "adding the new tool to the toolbox of cognitive science."(Clark, 1997, p175) rather than replacing the tool which is used now.( also see Vera\& Simian, 1993)

Ecological approaches to understanding the mind focus on the relationship between mind and environment. Brighton\& Todd give a quite plain and concrete explanation: We have explored one form of this relationship, in which simple mental mechanisms can make adaptive decisions by exploiting the characteristics of environments. As such, the concept of ecological rationality proves closely tied with the key dimensions that characterize situated approaches to understanding the mind. To examine this connection, we began by considering three metaphors that have been used to characterize the relationship between mind and environment: mirrors, lenses, and scissors. Mirrors reflect fundamental features of the world such that aspects of mind are shaped by the external environment. Here, minds represent useful and ubiquitous properties of the world, and these 
properties help the mind to function in environments. A lens projects rather than reflects, and reconstructs a representation of a distal stimulus on the basis of the current proximal cues. Again, by projecting aspects of the environment into the mind, the environment can be acted on by processing this information. Scissors are different. The scissors metaphor captures a relationship in which properties of the environment are exploited by, rather than represented by, the capabilities of the agent. It is only in circumstances in which mind and environment fit together like the blades of a pair of scissors that this relationship works. We have argued that the scissors metaphor is often appropriate when considering high-level cognitive processing tasks such as decision making and inference. The concept of ecological rationality, realized using an adaptive toolbox of simple mechanisms, builds on this scissors metaphor. Simple decision heuristics that exploit features of natural environments perform very well and sometimes better than more conventional and complex models of inference. Mechanisms such as these are termed ecologically rational, and we have argued that the concept of ecological rationality is far more productive than conventional notions

\section{CONCLUSION}

The above essay is only a review on the core concept of the whole book. In fact, among these concepts the embodied mind is the key of the core concepts, from which many other notions have derived. These notions are related to each other and mutually influence, some of which are partly overlapped whose angers of view, however, remain different.

Generally speaking, the theory of situated cognition is powerful, successful,in the respects of criticizing the traditional theories, with some empirical researches being quite convincible. There is, however, a lack of the establishment and argumentation of the theory itself, especially as to the strong notion of embodied mind,there are quite a few people who remain in doubt. Comparatively speaking, the extended mind is challenged even more. As kirsh. $(2009,303)$ points out: All efforts at creating a substantive theory of problem solving have been underspecified or fragmentary. And it is too early to know whether the next dominant theory will bear a situationalist stamp. However, we hold that what kirsh said above is a little bit overeacted.

The contribution of the theory of situated cognition to the cognitive science has been recognized by more and more people. For example, in terms of the views on the embodied mind,the explanation of the language comprehension is really refreshing.

Here we would like to give a brief statement of the psychological simulation as an example.

\subsection{Zwaan \& Kaschak (2009) Point Out}

Language is a uniquely human tool. It helps us situate ourselves in the world around us by directing our attention to people, objects, events, and possibilities for action. Language also situates us in worlds separate from our immediate environment. Through descriptions of real or imagined events, it serves to draw our attention to people, objects, events, and possibilities for action that are not present in the here and now. This situating of oneself in events outside of the here and now takes place through a process of mental simulation. Mental simulation can be considered a vicarious experiencing of the events being described. Language is a sequence of stimuli that orchestrate the retrieval of experiential traces of people, places, objects, events, and actions. This retrieval occurs in part via a rapid, direct, and passive memory process similar to the resonance process described by Hintzman (1986). The experiential traces reflect the comprehenders' past experience with particular objects, actions, and events, as well as their previous experience with language. (p368)

Recent researches point to the conclusion that the mental simulation ability ( and its result) is of the upmost importance to our plan and implementing behaviour, and understanding other people's behaviour.(Flanagan \& Johansson, 2003; Dolpert, Doya \& Kawato, 2003) (p368)

There is a good deal of evidence that language processing brings about the presonance of perceptual, motoric, and experiential traces in the comprehender. This evidence has been found at the word, sentence, and discourse levels. We argue that this evidence can be coherendy explained by assuming that language comprehension is grounded in the same neural systems that are used to perceive, plan, and take action in the external world. In this way, the comprehension of language involves the vicarious experiencing of the people, objects, emotions, and events that are described in the text. More broadly, just as our ability to plan and take action in the world relies on the ability to anticipate likely 
changes that will occur in the environment, we argue that an essential part of the language comprehension process is the ability to anticipate what is coming next, both in the linguistic input and in the situations that are being described. This process of presonance is immediate and effortless. It allows us to resituate ourselves and vicariously experience (and learn from) events that have happened in situations other than the one we currendy find ourselves in. (Zwaan \& Kaschak) (p377)

As Kirsh $(2009,303)$ points out : Building on the critique presented in Part One and Part Two, I posed a set of questions and initial approaches that might indicate the direction situated research should pursue next. These include an analysis of hints and scaffolds, symbolic affordances and mental projection, thinking with things, self-cueing and metacognition, and an enactive theory of thought. Some of these studies are being undertaken outside of cognitive and computational psychology. They explore how people interactively populate situations with extra resources and how they exploit those resources to simplify reasoning. Some of these studies, however, are not yet being undertaken. The bottom line, it seems to me, is that it is not enough that we recognize the central insight of situated cognition - that the environment provides organization for cognitive activity, that the world enables and supports such activities.

It is with pleasure to see that the theory and practice of the situated cognition based on the core concept has produced great influence, which is a fact without argument. As the researchers in the different fields cooperate with efforts, the study of the situated cognition will definitely get impressive and fruitful results.

\section{REFERENCES}

[1] Adams, F., \& Aizawa, K. The bounds of cognition[M]. Oxford:Blackwell,2008.

[2] Anderson, A., Garrod, S.C., \& Sanford, A.J.The accessibility of pronominal antecedents as a function of episode shifts in narrative text[J]. Quarterly Journal of Experimental psychology, 1983,35A, 427-440.

[3] Anderson, M. L.Embodied cognition: A field guide[M].Artificial Intelligence, 2003(149):91-130.

[4] Ashby, W.R. Introduction to cybernetics[M]. New York: Wiley, 1956.

[5] Ballard, D. H., Hayhoe, M. M., Pook, P. K., \& Rao, R. P. N. Deictic codes for the embodiment of cognition [J]. Behavioral and Brain Sciences, 1997,20,723-742.

[6] Beer, R.D. A dynamical systems perspective on agent-environment interaction[M]. Artificial Intelligence, 1995,72,172-215.

[7] Brighton, H., \& Todd, P.M. Situating Rationality, Ecologically Rational Decision Making with Simple Heuristics[M]. In P. Robbins., \& M. Aydede(Eds.), The Cambridge Handbook of Situated Cognition(PP322-346),Cambridge: Cambridge University Press, 2009.

[8] Cacioppo, J.T., Priester, J.R., \& Bernston, G.G.Rudimentary determination of attitudes: II. Arm flexion and extension have differential effects on attitudes[J]. Journal of Personality and Social Psychology, 1993, 65,5-17.

[9] Carreiras, M., Carriedo, N., Alonso, M.A., \& Fernandez, A. The role of verbal tense and verbal aspect in the foregrounding of information in reading[J]. Memory and Cognition, 1997,23,438-446.

[10] Chen, S., \& Bargh, J. A. Consequences of automatic evaluation: Immediate behavior dispositions to approach or avoid the stimulus[J]. Personality and Social Psychology Bulletin, 1999,25, 215-224.

[11] Clancey, W.J.Scientific Antecedents of Situated Cognition[M]. In P. Robbins \& M. Aydede (Eds.), The Cambridge Handbook of Situated Cognition (PP11-34). Cambridge: Cambridge University Press,2009.

[12] Clark, A.Moving minds: Situating content in the service of real-time success[M]. In J.Tomberlin(Ed.), Philosophical perspectives: Vol. 9. AI, connectionism, and philosophical psychology (pp. 89-104). Atascadero, CA: Ridgeview,1995.

[13] Clark, A. Being there: Putting brain, body, and world together again[M]. Cambridge, MA: MIT Press, 1997.

[14] Clark, A. Magic words: How language augments human computation[A]. In P. Carruthers \& J. Boucher(Eds.), Language and thought[C]: Interdisciplinary themes(pp.162-183). Cambridge: Cambridge University Press, 1998.

[15] Clark, A. Natural-born cyborgs[M]. Oxford: Oxford University Press, 2003.

[16] Clark, A.(1989). Microcognition[M]. Cambridge, MA: MIT Press.

[17] Clark, A.,\& Chalmers, D.The extended mind[J]. Analysis,1998,58,10-23.

[18] Eliasmith, C., \& Anderson, C.H.. Neural engineering: Computation, representation and dynamics in neurobiological systems[M]. Cambridge, MA: MIT Press,2003. 
[19] Eliasmith,C.Dynamics.Control,and Cognition[M].In P.Robbins., \& M.Aydede(Eds.), The Cambridge Handbook of Situated Cognition(PP134-154), Cambridge: Cambridge University Press,2009.

[20] Flanagan, J. R., \& Johansson, R.S. Action plans used in action observation [J]. Nature, 2003, 424, 769-771.

[21] Gallagher, S. Philosophical Antecedents of Situated Cognition [M]. In P. Robbins \& M. Aydede (Eds.), the Cambridge Handbook of Situated Cognition (PP35-51). Cambridge: Cambridge University Press, 2009.

[22] Grounding language in action[J]. Psychonomic Bulletin and Review, 9,558-565.

[23] Gu, Y.Self-introduction Gu Yueguo's Antnology on Linguistics [M]. Foreign Language Teaching and Research Press, 2010.

[24] Harnad, S. The symbol grounding problem [J]. Physica D, 1990, 42:335-346.

[25] Hintzman,D. L. "Schema-abstraction" in a multiple trace model[J]. Psychological Review, 1986, 93: 411428.

[26] Horton, W. S., \& Rapp. D. N. Occlusion and accessibility of information in narrative comprehension [J]. Psychonomic Bulletin \& Review, 2002, 10:104-109.

[27] Husserl, E. Ideen zu einer reinen phanomenologie und phanomenologischen philosophie [J]. Zweites Buch. (M. Biemel, Ed.), Husserliana IV. The Hague: Martinus Nijhoff, 1952.

[28] Kaup, B., \&Zwaan, R.A. Effects of negation and situational presence on the accessibility of text information [J]. Journal of Experimental Psychology: Learning, Memory, and Cognition, 2003, 23:439-446.

[29] Kirsh, D. The intelligent use of space[J]. Artificial Intelligence, 1995, 7:31-68.

[30] Kirsh, D. Problem Solving and Situated Cognition [M]. In P. Robbins., \& M. Aydede (Eds.), The Cambridge Handbook of Situated Cognition (PP264-306),Cambridge: Cambridge University Press,2009.

[31] Lakoff, G., \& Johnson, M. Philosophy in the flesh [M]. New York: Basic Books, 1999.

[32] Markman, A.B., \& Dietrich, E. Extending the classical view of representation [J]. Trends in Cognitive Sciences, 2000, 4:470-475.

[33] McClamrock, R. Existential cognition: Computational minds in the world [M]. Chicago: University of Chicago Press, 1995.

[34] Merleau-Ponty, M. Phenomenology of perception (C.Smith, Trans.) [M]. London: Routledge \& Kegan Paul,1962.

[35] Morrow, D. G., Bower, G. H., \& Greenspan, S. L. Updating situation models during narrative comprehension [J]. Journal of Memory and Language, 1989,28,292-312.

[36] Morrow, D. G., Greenspan, S. E., \& Bower, G. H. Accessibility and situation models in narrative comprehension [J]. Journal of Memory and Language, 1987, 26:165-187.

[37] Myin, E \& O’Regan, J.K.Situated Perception and Sensation in Vision and Other Modalities [M]. In P. Robbins., \& M.Aydede(Eds.),The Cambridge Handbook of Situated Cognition(PP185-200), Cambridge: Cambridge University Press,2009.

[38] Niedenthal, P.M., Barsalou, L. W., Winkielman, P., Krauth-Gruber, S., \& Ric, F. Embodiment in attitudes, social perception, and emotion [J]. Personality and Social Psychology Review, 2005,9:184-211.

[39] O'Regan, J.K. Solving the "real" mysteries of visual perception: The world as an outside memory [J]. Canadian Journal of Psychology, 1992, 46:461-488.

[40] Port, R., \& van Gelder, T. (Eds.). Mind as motion: Explorations in the dynamics of cognition [M]. Cambridge, MA: MIT Press, 1995.

[41] Rinck, M., \& Bower, G. H. Temporal and spatial distance in situation models [J]. Memory and Cognition, 2000, 28:1310-1320.

[42] Robbins, p., \& Aydede, M. The Cambridge Handbook of Situated Cognition [M]. Cambridge: Cambridge University Press, 2009.

[43] Robbins, P., \& Aydede. M. A Short Primer on Situated Cognition. In P. Robbins \& M. Aydede (Eds.) [J]. The Cambridge Handbook of Situated Cognition2009:3-10.

[44] Rupert, R. Innateness and the Situated Mind. In P.Robbins., \& M.Aydede(Eds.), The Cambridge Handbook of Situated Cognition(PP96-116) [M].Cambridge: Cambridge University Press,2009.

[45] Smith, B.C. Situatedness/embeddedness. In R. A. Wilson \& F.C. Keil(Eds.), The MIT encyclopedia of the cognitive sciences(pp. 769-770) [M]. Cambridge, MA: MIT Press, 1999.

[46] Smith, E. R., \& Conrey. F. R. The Social Context of cognition. In p. Robbins \& M. Aydede (Eds.), the Cambridge Handbook of Situated Cognition (PP454-466) [M]. Cambridge: Cambridge University Press, 2009.

[47] Smith, E.R., \& Semin, G. R. Socially situated cognition. Cognition in its social context [J]. Advances in Experimental Social Psychology, 2004, 36:53-117. 
[48] The Cambridge Handbook of Situated Cognition[C]. Edited by Dr. Robbins and Dr. Aydede, 2009.

[49] Thelen, E., \& Smith, L. B. A dynamic systems approach to the development of cognition and action [M]. Cambridge, MA: MITPress, 1994.

[50] Thomas, N. Are theories of imagery theories of imagination? An active perception approach to conscious mental content[J]. Cognitive Science, 1999,23: 207-245.

[51] Trabasso, T., \& Suh, S. Understanding text: Achieving explanatory coherence through on-line inferences and mental operations in working memory[J]. Discourse Processes, 1993,16: 3-34

[52] Van Gelder, T. What might cognition be, if not computation? [J].Journal of Philosophy,1995,91:345381.

[53] Vera, A. H., \& Simon, H. A. Situated action: A symbolic interpretation [J]. Cognitive Science, 1993,17:748.

[54] Wiener, N.Cybernetics; or, Control and communication in the animal and the machine [M].New York:Wiley, 1948.

[55] Wilson, M.Six views of embodied cognition [J]. Psychonomic Bulletin and Review, 2002, 9:625-636.

[56] Wolpert, D. M., Doya, K., \& Kawato, M.. A unifying computational framework for motor control and social interaction[J]. Phlosophical Transactions of the Royal Society, 2003,358:593-602.

[57] Young, J. Z. (1964). A model of the brain [M]. Oxford: Oxford University Press.

[58] Zwaan, R. A. \& Kaschak, M.P.Language in the Brain, Body, and World. In P. Robbins \& M. Aydede(Eds). The Cambridge Handbook of Situated Cognition(PP368-381) [M]. Cambridge: Cambridge University Press, 2009.

[59] Zwaan, R. A., Madden, C. J., \& Whitten, S. N. The presence of an event in the narrated situation affects its activation[J]. Memory and Cognition, 2000,28:1022-1028.

[60] Zwaan, R.A. Processing narrative time shifts [J]. Journal of Experimental Psychology: Learning, Memory, and Cognition, 1996,22:1196-1207.

\section{AUTHOR'S BIOGRAPHY}

Dr. WU Guoliang, PhD, Professor of Zhejiang Yuexiu University of Foreign Languages, PhD Supervisor of Zhejiang University, Distinguished Visiting Professor of Arkansas State University, USA. His main interest includes Linguistics, Pragmatics, and translation. Address to No.428 Kuaiji Road, Yuecheng District, Shaoxing, Zhejiang, 312000, China.

Citation: WU Guoliang. "A Review of the Core Concept of the Cambridge Handbook of Situated Cognition" International Journal on Studies in English Language and Literature (IJSELL), vol 8, no. 6, 2020, pp. 1-11. doi: http://dx.doi.org/10.20431/2347-3134.0806001.

Copyright: (C) 2020 Authors. This is an open-access article distributed under the terms of the Creative Commons Attribution License, which permits unrestricted use, distribution, and reproduction in any medium, provided the original author and source are credited. 